\title{
Prevalence of Trichinella britovi in muscle tissue samples from foxes from Podkarpackie Voivodeship,
} Poland

\author{
JAN WIŚNIEWSKI, ZBIGNIEW BEŁKOT*, BLANKA ORŁOWSKA, JANUSZ BOGDAN, \\ MIROS $Ł A W ~ W E L Z * * *$, STANIS $\measuredangle A W ~ K A C Z O R^{* * *}$, MAREK NOWICKI, MARTYNA PUCHALSKA, \\ MICHAŁ TRACZ, MIROSŁAW RÓŻYCKI**, EWA CHMURZYŃSKA**, EWA BILSKA-ZAJĄ ${ }^{* *}$, \\ KRZYSZTOF ANUSZ
}

\author{
Department of Food Hygiene and Public Health Protection, Faculty of Veterinary Medicine, \\ Warsaw University of Life Sciences - SGGW, Nowoursynowska 159, 02-776 Warsaw \\ *Department of Food Hygiene of Animal Origin, Faculty of Veterinary Medicine, University of Life Sciences in Lublin, \\ Akademicka 12, 20-950 Lublin \\ **Department of Parasitology and Invasive Diseases, National Veterinary Research Institute in Puławy, \\ Aleja Partyzantów 57, 24-100 Puławy \\ ${ }^{* * *}$ Voivodeship Veterinary Inspectorate in Krosno, ks. Piotra Ściegiennego 6 A, 38-400 Krosno
}

Wiśniewski J., Bełkot Z., Orłowska B., Bogdan J., Welz M., Kaczor S., Nowicki M., Puchalska M., Tracz M., Różycki M., Chmurzyńska E., Bilska-Zając E., Anusz K.

Prevalence of Trichinella britovi in muscle tissue samples from foxes from Podkarpackie Voivodeship, Poland

\section{Summary}

The aim of the study was to detect Trichinella larvae in muscle tissue samples of red foxes (Vulpes vulpes) living in Podkarpackie Voivodeship and to determine their species composition. Muscle tissue samples had been collected from a total number of 139 red foxes culled during 2011-2012 in Podkarpackie Voivodeship and studied for the presence of Trichinella. Ten-gram muscle tissue samples were collected from each animal, combined into a fifty-gram pooled sample and then tested for the presence of Trichinella by the reference method for pooled sample digestion with a magnetic stirrer. Whenever a pooled sample gave a positive result, the suspected animals were resampled, and each ten-gram muscle tissue sample was tested separately. Trichinella larvae were identified to species by Multiplex PCR. The studies revealed the presence of one Trichinella larva in a pooled sample composed of five individual samples from foxes culled in the following locations: Leszczowate in Bieszczadzki District (one sample), Szczutków in Lubaczowski District (two samples), Podemszczyzna in Lubaczowski District (one sample) and Strzyżów in Strzyżowski District (one sample). No Trichinella larvae were detected during the test carried out on individual samples that composed the pooled sample. Numerous Trichinella larvae were found in samples from 4 foxes coming from Berezka and Glinka in Leski District, Dybawka in Przemyski District, and Golcowa in Brzozowski District. All Trichinella larvae isolated from the foxes belonged to the species $T$. britovi. The study confirmed the role of foxes as an important vector of Trichinella larvae circulating in the habitat of humans and animals. T. britovi is a species occurring most frequently in the fox population.

Keywords: Trichinella, red fox, Trichinella britovi, Vulpes vulpes

Trichinosis is still one of the most important parasitoses affecting different animal species and taking the form of zoonosis. It is also one of the six diseases listed as specific hazards in Regulation (EC) No 854/2004 of the European Parliament and of the Council of 29 April 2004 laying down specific rules for official controls of products of animal origin intended for human consumption (Chapter IX, letter C). In Poland, Trichinella are most commonly reported for wild boars, and these are mainly $T$. spirali and T. britovi. Sometimes infection with both species takes place. There are also known parasitic infections with T. pseudospiralis (3, 12). Among foxes in Poland, the prevailing Trichinella is T. britovi, and T. spiralis is the second most abundant species. One mixed T. spiralis/T. britovi infection has also been detected, as well as one quite uncommon 
case of infection with T. nativa, a species more typical of the arctic zone and characterized by significant resistance to low temperatures. It was the first case this species was reported in Poland $(3,6,7)$. Other studies have revealed the presence of $T$. spiralis and $T$. britovi in wild carnivores and omnivores, such as badgers, martens and raccoons. A case of a fox infected with T. pseudospiralis has also been reported in Poland (17).

The aim of the study was to detect Trichinella larvae in muscle tissue samples from red foxes (Vulpes vulpes) living in Podkarpackie Voivodeship and to determine their species composition.

\section{Material and methods}

Podkarpackie Voivodeship is a foothill region in southeastern Poland, bordering with Ukraine and Slovakia. It is one of the most forested Polish regions, with beech and fir trees in the mountainous south and pine trees in the flat north. Forests of Podkarpackie constitute one of the most important habitats for wildlife in Poland.

The study material consisted of muscle tissue samples of the rumen and diaphragm collected from a total 139 foxes culled during 2011-2012 at different locations of Podkarpackie Voivodeship. In the first stage of the study ten-gram muscle tissue samples were collected from each animal. Then, the samples were combined into fifty-gram pooled samples and tested for the presence of Trichinella by the reference method for pooled sample digestion with a magnetic stirrer, stipulated in Regulation (EC) No 2075/2005 of the European Parliament and of the Council of 5 December 2005 laying down specific rules for official controls for Trichinella in meat. In case of detecting Trichinella in a pooled, 50-gram sample, each 10-gram component sample was recollected and tested separately. The isolated Trichinella larvae were identified to species according to the following procedure. From each positive sample obtained during digestion, and whenever possible,

\section{Tab. 1. Primer mixture}

\begin{tabular}{|r|l|c|c|}
\hline №. & \multicolumn{1}{|c|}{ Primer sequence } & Primer code & Primer target \\
\hline 1 & 5'GTTCCATGTGAACAGCAG3' & Cp-I.F & ESV \\
2 & 5'CGAAAACATACGACAACTGC3' & Cp-I.R & \\
3 & 5'GCTACATCCTGATCTGTT3' & Cp-II.F & ITS1 \\
4 & 5'AGACACAATATCAACCACAGTACA3' & Cp-II.R & \\
5 & 5'GCGGAAGGATCATTATCGTGTA3' & Cp-III.F & ITS1 \\
6 & 5'TGGATTACAAAGAAACCATCACT3' & Cp-IIIR & \\
7 & 5'GTGAGCGTAATAAAGGTGCAG3' & Cp-IV.F & ITS2 \\
8 & 5'TTCATCACACATCTTCCACTA3' & Cp-IV.R & \\
\hline 9 & 5'CAATTGAAAACCGCTTAGCGTGTTT3' & Cp-V.Ff & ITS2 \\
\hline 10 & 5'TGATCTGAGGTCGACATTTCC3' & Cp-V.R & \\
\hline
\end{tabular}

5 Trichinella larvae were collected for further analysis. DNA was extracted from individual larvae by means of DNA IQ ${ }^{\mathrm{TM}}$ System Kit Promega code DC6701 and Tissue and Hair Extraction Kit, Promega code DC6740. The molecular identification of DNA from individual larvae was carried out by multiplex-PCR analysis according to a standard protocol provided by the European Union Reference Laboratory for Parasites, Rome, Italy (EURLP), and with the use of primers presented in Tab. 1 .

PCR products were separated by electrophoresis on $2 \%$ agarose gel containing ethidium bromide at an approximate concentration of $5.0 \mu \mathrm{l} / 100 \mathrm{ml}$ liquid gel. Molecular weight standards were provided by Gene Ruler ${ }^{\mathrm{TM}} 100 \mathrm{bp}$ DNA Ladder (Fermentas). Trichinella species-specific molecular weight markers are given in Tab. 2.

\section{Results and discussion}

The study revealed the presence of one larva in a pooled sample comprising 5 individual samples collected from foxes culled in Leszczowate in Bieszczadzki District (one sample), Szczutków (two samples) and Podemszczyzna (one sample) in Lubaczowski District and Strzyżów in Strzyżowski District (one sample). Further attempts to detect Trichinella in individual 10 -gram samples proved unsuccessful. Numerous Trichinella larvae were also found in 5 foxes from Leski District (4 from Berezka and 1 from Glinka), in 1 fox from Przemyski District (Dybawka) and in 1 fox from Brzozowski District (Golcowa). All the Trichinella larvae isolated belonged to the species T. britovi. For all the larvae, molecular weights of mPCR products ranged from 173 to $273 \mathrm{bp}$, which is typical of the DNA of $T$. britovi larvae (Fig. 1).

Trichinella infections in foxes, especially with T. britovi, have been confirmed by numerous publications referring to different European regions and countries. After 2000, in Poland too, there have been reports on the occurrence of different species of Trichinella larvae in foxes, with the predominant presence of T. britovi $(5,6,12,19)$. Studies conducted during 2005-2006 in Slovakia aimed to determine the incidence of Trichinella-infected foxes living in the wild in particular regions of the country. The number of infected foxes was the lowest in lowland areas $(6.9 \%)$ and the highest in mountainous regions (from 14.2 to $25.2 \%$, depending on the location), with an average of $15.6 \%$ for the whole country (13). Further studies confirmed an increase in Trichinella prevalence in foxes, as well as the dominant status of $T$. britovi among Trichinella species circulating in the sylvatic environment (14). A study conducted in Belarus during 1981-2001 on carcasses of 94 foxes coming from the

Tab. 2. Molecular weight markers of particular Trichinella species

\begin{tabular}{|c|c|c|c|c|c|c|c|c|c|}
\hline Marker & T. spiralis & T. nativa & T. britovi & T. pseudospiralis & T. murelli & T6 & T. nelsoni & T. papue & T. zimbabwensis \\
\hline ESV & 173 & 127 & 127 & $310-350$ & 127 & 127 & 127 & 240 & 264 \\
ITS1 & & & 253 & & & 210 & & & \\
ITS2 & & & & & 316 & & 404 & & \\
\hline
\end{tabular}




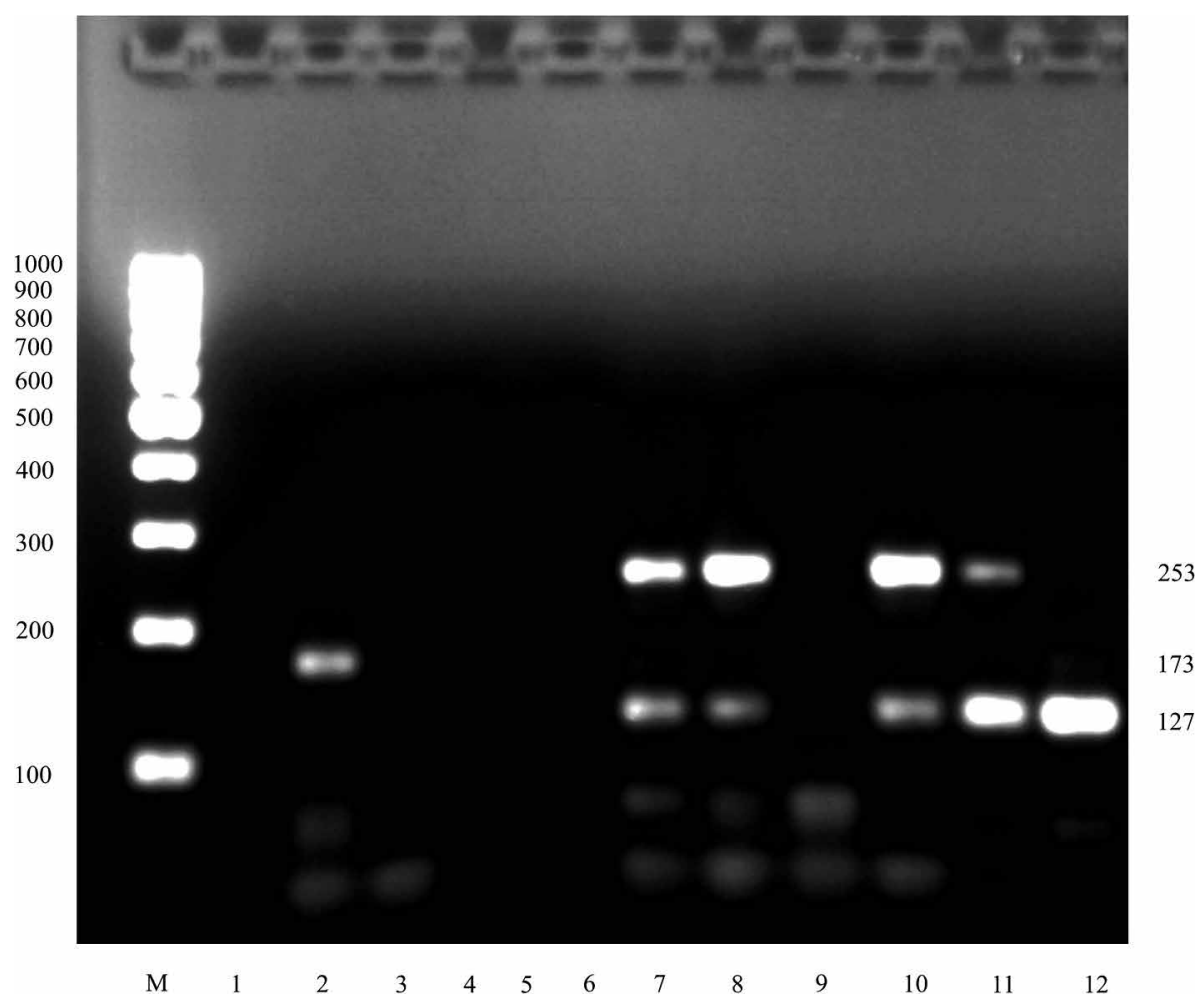

Fig. 1. Electropherogram of PCR products for Trichinella species identification Explanations: $\mathrm{M}$ - marker 100-1000 bp; 1 - negative control; 2 - T. spiralis control; 3, 4, 5, 6- negative controls; 7, 8, 10, $11-T$. britovi; 9 - no PCR reaction were infected with T. spiralis, $31 \%$ with $T$. britovi, and the remaining $16 \%$ had mixed infections with both species (30). T. britovi was also found in foxes culled within the area of Belgrade ( 2 individuals) and in the Kucevo region (1 individual). In Hungary, the prevalence of Trichinella was found to vary between different regions of the country, with the highest values in north-eastern areas neighbouring with Slovakia and Ukraine, lower values in the southern part of the country bordering with Croatia, Serbia and Romania, and the lowest values in north-western and central Hungary. The highest proportion of the isolated Trichinella species was $T$. britovi $(85.7 \%)$, and the second most abundant was $T$. spiralis (11.4\%). The only case of $T$. pseudospiralis was a fox culled in the Szabolcs-Szatmar region $(27,28)$. Studies carried out in Estonia during 1992-1999 involved muscle tissue samples collected from both wild and southern part of the country showed the prevalence of Trichinella, but their species composition was not determined (26). During 1998-2000, north-western, European regions of Russia were investigated in a study of the prevalence of Trichinella in different animal species. The samples examined in this study came from 184 animals, including 82 wolves, 29 foxes, 55 martens, as well as some raccoons and dogs. Ninetyeight animals were Trichinella-positive (53.3\%). The highest prevalence of Trichinella was detected in wolves $(97.5 \%)$, with $T$. britovi being the most frequently (98\%) isolated species (21). In view of the above, $T$. britovi from Russia might be associated with the sylvatic habitat. The above studies corroborate the key role of $T$. britovi in the sylvatic habitat and suggest that, in addition to foxes, wolves are a potentially important vector in circulating Trichinella in wildlife. In this regard, the wolf seems particularly important considering the fact that its population in Poland has increased significantly, and nowadays it can be found practically across the country. Among free-ranging animals in Romania, the prevalence of Trichinella was found the highest among wolves, followed by cats and foxes, and again T. britovi was the predominant species (4). Out of the T. britovi isolates collected by the International Trichinella Reference Center (ITC), 35 (94.6\%) were obtained from foxes coming from Romania. Samples collected during 2009-2010 from free-ranging animals from the Braničevo region in Serbia revealed the presence of Trichinella in $11.7 \%$ of wild boars, $12.3 \%$ of foxes and in each of three wolves tested. Fifty-three percent of animals tested domestic animals from 15 different regions. The results confirmed a high, 79.4\% prevalence of Trichinella among animals from sylvatic habitats. Infections with T. spiralis, T. nativa and T. britovi were found in raccoons, foxes, lynx and wolves (15). Out of the eight Trichinella isolates comprising the collection of ITC, five are T. britovi $(62 \%)$, two are T. native $(25 \%)$, and one is a mixed, $T$ native/T. britovi infection (12.5\%). In samples collected during 1985-2003 in Sweden from free-ranging animals, Trichinella was revealed in 4.5\% of red foxes, $16.7 \%$ of polar foxes, $14.3 \%$ of grey wolves, $5 \%$ of lynx and $0.05 \%$ of wild boars. The presence of all four species of Trichinella reported from Europe, namely T. spiralis, $T$. nativa, $T$. britovi, T. pseudospiralis, was confirmed for the territory of Sweden. Out of 18 isolates of Trichinella derived from foxes from Sweden, 7 were T. britovi (38\%), 5 were T. nativa (28\%), 1 was T. spiralis $(14 \%)$, and 4 were mixed infections, including 2 infections with $T$. natival T. britovi (11\%) and 2 infections with $T$. natival T. spiralis (11\%) (22). During 1999-2005, muscle tissue samples were taken in Finland from free-ranging raccoons, red foxes, lynx, brown bears, wolves and badgers to be tested for the presence of Trichinella. As in Sweden, the presence of T. spiralis, T. nativa, T. britovi, T. pseudospiralis was shown. The populations of raccoons and red foxes were the most important Trichinella reservoirs. The most frequently detected species was $T$. nativa $(74 \%)$, followed by T. spiralis $(12 \%)$, T. britovi $(6 \%)$ and T. pseudospiralis $(1 \%)$. The raccoon was the host to all four Trichinella species, and it also showed the highest rate of 
Trichinella larvae invasion $(1,18)$. Samples examined for the presence of Trichinella in Norway were collected from 393 foxes during hunting seasons 1994, 1995, 2002-2005. Larvae of the parasite were detected in 19 foxes, giving a prevalence ratio of $4.8 \%$. In 18 cases, the species found was T. native, and in one case it was T. britovi. The prevalence of Trichinella in foxes was significantly higher in eastern Norway (9). Similar studies conducted in Denmark involved samples collected during 1995-1996 and 1997-1998 from 6141 foxes hunted throughout the country, except the island of Bornholm. Larvae of Trichinella were present in only 3 samples collected during 1995-1996 from animals from northwestern Denmark. Owing to the low invasion rate, these Trichinella larvae were not identified to species (10). Studies on the prevalence of Trichinella in wild carnivores in Switzerland involved samples collected from 1298 foxes during 2006-2007 and from 55 lynx in 1999 and 2007. Trichinella larvae were found in $1.6 \%$ of the foxes and in $27.3 \%$ of the lynx. In all cases, the Trichinella species detected was T. britovi. The foxes infected with Trichinella were the most numerous in the central and western regions of the country, and badgers in the western regions (11). Studies of the prevalence of Trichinella among red foxes, martens and badgers in the Italian Alps showed infections with T. britovi (24). Screening for Trichinella britovi infection in red foxes and wild boars from HautVar, southeastern France, was carried out on samples collected during 2006-2009 from 108 red foxes and 894 wild boars. The prevalence of $T$. britovi was determined at a level of $2.7 \%$ for red foxes (2). In 2004, the prevalence of T. britovi infections in domestic pigs and a fox were reported from Corsica, the island previously known as a territory free from Trichinella (25). Studies on the prevalence of Trichinella larvae in foxes have also been conducted in Spain. At the end of the $20^{\text {th }}$ century, the presence of $T$. spiralis larvae was reported in $8.9 \%$ of 67 foxes from central Spain. Among the animals from the south-western part of the country, $3 \%$ of 227 individuals studied were infected with Trichinella larvae. In this case, Trichinella infections involved two species, T. britovi and T. spiralis, responsible for $67 \%$ and $33 \%$ of all infections, respectively $(8,20)$. During 1998-2007, samples collected from 1319 red foxes from north-eastern Spain were tested for Trichinella. The results revealed only 4 cases of Trichinella infection: two in 2006, one in 1999 and one in 2002. The species responsible for the two cases in 2006 was T. britovi (16). A study conducted in Ireland, 30 years after the last reported cases of Trichinella in animals and humans, involved samples from 454 foxes from different counties. T. spiralis was found in four animals ( 2 from Cork County, 1 from Donegal County and 1 from Waterford County) (23). Other studies, in 2003/2004 and 2007/2008, carried out on samples collected from 443 red foxes across
Northern Ireland revealed only one case of Trichinella infection. The larvae found belonged to the species T. spiralis (29). The analysis indicates $T$. britovi as the dominant Trichinella species in the fox population of the temperate climate. Are then foxes to be considered potential Trichinella vectors to breeding pigs?

Over 150 documented T. britovi-related trichinosis cases in pigs prove that, although considered typical of wildlife habitats, Trichinella may also be involved in the livestock life cycle. Whether foxes are direct or indirect Trichinella vectors to livestock remains unclear.

Currently, it is the red fox, whose population has recently increased significantly, that appears to be the main reservoir of trichinosis for wild animals in Poland. The growing population of foxes, which increased from 55000 in 1990 to 200000 at present, could pose an epidemiological threat. Foxes have moved into suburban areas and have become a link between the human habitat and wildlife. Studies from Podkarpackie Voivodeship and other voivodeships are consistent and corroborate that $T$. britovi is the dominant species among Trichinella affecting foxes in Poland. The high prevalence of $T$. britovi in foxes, compared with wild boars, suggests the presence of two different cycles of Trichinella in natural habitats. Whether foxes play the key role as Trichinella vectors to humans and livestock remains an open question, as the high prevalence of T. britovi in foxes does not directly translate into its prevalence in pigs.

To date, only 2 cases of trichinosis reported for pigs in Poland have been caused by T. britovi. Although the results of the present study provide only a partial picture of trichinosis in Poland, the growing population of the red fox in Poland, its expansion to urban areas and global warming, all support the hypothesis of an increased rate of $T$. britovi in pigs in the nearest future.

\section{References}

1. Airas N., Saari S., Mikkonen T., Virtala A. M., Pellikka J., Oksanen A., Isomursu M., Kilpelä S. S., Lim C. W., Sukura A.: Sylvatic Trichinella spp. infection in Finland. J. Parasitol. 2010, 96, 67-76.

2. Aoun O., Lacour S. A., Levieuge A., MariéJ. L., Vallée I., Davoust B.: Screening for Trichinella britovi infection in red fox (Vulpes vulpes) and wild boar (Sus scrofa) in southeastern France. J. Wildl. Dis. 2012, 48, 223-225.

3. Balicka-Ramisz A., Grupiński T., Ramisz A., Pilarczyk B., Laurans L.: Prevalence of Trichinella spp. in red foxes and wild boars in the northwestern part of Poland. Dtsch. Tierarztl. Wochenschr. 2007, 114, 354-357.

4. Blaga R., Gherman C., Cozma V., Zocevic A., Pozio E., Boireau P.: Trichinella species circulating among wild and domestic animals in Romania. Vet. Parasitol. 2009, 159, 218-221.

5. Cabaj W.: Wild and domestic animals as permanent Trichinella reservoir in Poland. Wiad. Parazytol. 2006, 52, 175-179.

6. Cabaj W., Moskwa B., Pastusiak K., Malczewski A.: Trichinellosis in wild animals and domestic pigs in Poland. Med. Weter. 2004, 60, 80-83.

7. Chmurzyńska E., Różycki M., Bilska-Zając E., Nöckler K., Mayer-Scholl A., Pozio E., Cencek T., Karamon J.: Trichinella nativa in red foxes (Vulpes vulpes) of Germany and Poland: Possible different origins. Vet. Parasitol. 2013, 198, 254-257.

8. Criado-Fornelio A., Gutierrez-Garcia L., Rodriguez-Caabeiro F., ReusGarcia E., Roldan-Soriano M. A., Diaz-Sanchez M. A.: A parasitological survey of wild red foxes (Vulpes vulpes) from the province of Guadalajara, Spain. Vet. Parasitol. 2000, 92, 245-251. 
9. Davidson R. K., Gjerde B., Vikøren T., Lillehaug A., Handeland K.: Prevalence of Trichinella larvae and extra-intestinal nematodes in Norwegian red foxes (Vulpes vulpes). Vet. Parasitol. 2006, 136, 307-316.

10. Enemark H. L., Bjørn H., Henriksen S. A., Nielsen B.: Screening for infection of Trichinella in red fox (Vulpes vulpes) in Denmark. Vet. Parasitol. 2000, 88 229-237.

11. Frey C. F., Schuppers M. E., Müller N., Ryser-Degiorgis M. P., Gottstein B.: Assessment of the prevalence of Trichinella spp. in red foxes and Eurasian lynxes from Switzerland. Vet. Parasitol. 2009, 159, 295-299.

12. Golińska Z. E.: Występowanie nowych gatunków rodzaju Trichinella u zwierzat i ludzi. Med. Weter. 2003, 59, 568-570.

13. Hurníková Z., Bartková D., Dubinský P.: Analysis of the epidemiological factors influencing vulpine trichinellosis in ecologically different regions of Slovakia. Wiad. Parazytol. 2006, 52, 213-218.

14. Hurníková Z., Dubinský P.: Long-term survey on Trichinella prevalence in wildlife of Slovakia. Vet. Parasitol. 2009, 159, 276-280.

15. Järvis T., Miller I., Pozio E.: Epidemiological studies on animal and human trichinellosis in Estonia. Parasite 2001, 8, 86-87.

16. López-Olvera J. R., Vives L., Serrano E., Fernández-Sirera L., Picart L., Rossi L., Marco I., Bigas E., Lavín S.: Trichinella sp. in red foxes (Vulpes vulpes) from Catalonia, NE Spain. Parasitol. Res. 2011, 108, 1589-1591.

17. Moskwa B., Goździk K., Bień J., Borecka A., Gawor J., Cabaj W.: First report of Trichinella pseudospiralis in Poland in red foxes (Vulpes vulpes). Acta Parasitol. 2013, 58, 149-154.

18. Oivanen L., Kapel C. M., Pozio E., La Rosa G., Mikkonen T., Sukura A. Associations between Trichinella species and host species in Finland. J. Parasitol. 2002, 88, 84-88.

19. Okulewicz A., Hildebrand J., Okulewicz J., Perec A.: Red fox (Vulpes vulpes) as reservoir of parasites and source of zoonosis. Wiad. Parazytol. 2005, 51, $125-132$.

20. Pérez-Martín J. E., Serrano F. J., Reina D., Mora J. A., Navarrete I.: Sylvatic trichinellosis in southwestern Spain. J. Wildl. Dis. 2000, 36, 531-534.

21. Pozio E., Casulli A., Bologov V. V., Marucci G., La Rosa G.: Hunting practices increase the prevalence of Trichinella infection in wolves from European Russia. J. Parasitol. 2001, 87, 1498-1501.
22. Pozio E., Christensson D., Stéen M., Marucci G., La Rosa G., Bröjer C., Mörner T., Uhlhorn H., Agren E., Hall M.: Trichinella pseudospiralis foci in Sweden. Vet. Parasitol. 2004, 125, 335-342.

23. Rafter P., Marucci G., Brangan P., Pozio E.: Rediscovery of Trichinella spiralis in red foxes (Vulpes vulpes) in Ireland after 30 years of oblivion. J. Infect 2005, 50, 61-65.

24. Remonti L., Balestrieri A., Domenis L., Banchi C., Lo Valvo T., Robetto S., Orusa R.: Red fox (Vulpes vulpes) cannibalistic behaviour and the prevalence of Trichinella britovi in NW Italian Alps. Parasitol. Res. 2005, 97, 431-435.

25. Richomme C., Lacour S. A., Ducrot C., Gilot-Fromont E., Casabianca F., Maestrini O., Vallée I., Grasset A., van der Giessen J., Boireau P.: Epidemiological survey of trichinellosis in wild boar (Sus scrofa) and fox (Vulpes vulpes) in a French insular region, Corsica. Vet. Parasitol. 2010, 172, 150-154

26. Shimalov $V$. V., Shimalov $V$. T.: Helminth fauna of the red fox (Vulpes vulpes Linnaeus, 1758) in southern Belarus. Parasitol. Res. 2003, 89, 7-78.

27. Sréter T., Széll Z., Marucci G., Pozio E., Varga I.: Extraintestinal nematode infections of red foxes (Vulpes vulpes) in Hungary. Vet. Parasitol. 2003, 115 329-334.

28. Széll Z., Marucci G., Bajmóczy E., Cséplo A., Pozio E., Sréter T.: Spatia distribution of Trichinella britovi, T. pseudospiralis and T. spiralis in red foxes (Vulpes vulpes) in Hungary. Vet. Parasitol. 2008, 156, 210-215.

29.Zimmer I. A., Fee S. A., Spratt-Davison S., Hunter S. J., Boughtflower V. D., Morgan C. P., Hunt K. R., Smith G. C., Abernethy D., Howell M., Taylor M. A.: Report of Trichinella spiralis in a red fox (Vulpes vulpes) in Northern Ireland. Vet. Parasitol. 2009, 159, 300-303.

30. Zivojinovic M., Sofronic-Milosavljevic L. J., Cvetkovic J., Pozio E., Interisano M., Plavsic B., Radojicic S., Kulisic Z.: Trichinella infections in different host species of an endemic district of Serbia. Vet. Parasitol. 2013 194, 136-138.

Corresponding author: Dr Jan Wiśniewski, Ph. D., Department of Food Hygiene and Public Health Protection, Faculty of Veterinary Medicine, Warsaw University of Life Sciences - SGGW, Nowoursynowska 159, 02-776 Warsaw, Poland; e-mail: jan wisniewski1@sggw.pl 